Research Article

\title{
Calculation Method of Bonding Section of Joint Surface of Dangerous Rock Mass Based on Amplitude Ratio
}

\author{
Qingbo Li, ${ }^{1}$ Hongfei Wang $\mathbb{D}^{1,2}$ Mowen Xie $\mathbb{D}^{2},{ }^{2}$ and Weinan Liu $\mathbb{D}^{2}$ \\ ${ }^{1}$ Yellow River Engineering Consulting Co., Ltd. (YREC), Zhengzhou 450003, Henan, China \\ ${ }^{2}$ School of Civil and Resource Engineering, University of Science and Technology Beijing, Beijing 100083, China \\ Correspondence should be addressed to Hongfei Wang; wanghf_yrec@163.com and Weinan Liu; 1452798045@qq.com
}

Received 4 July 2020; Revised 11 November 2020; Accepted 17 November 2020; Published 1 December 2020

Academic Editor: Jiaxi Zhou

Copyright (c) 2020 Qingbo Li et al. This is an open access article distributed under the Creative Commons Attribution License, which permits unrestricted use, distribution, and reproduction in any medium, provided the original work is properly cited.

In this study, through an analysis of vibration response characteristics of joint surface stiffness on dangerous rock mass, the relationship formula between amplitude ratio of the dangerous rock mass to the bedrock and the length of the bonding section of the joint surface is determined. The stability of the rock mass can be evaluated by combining the formula with the existing rockmass limit equilibrium theory. This study proposes the existence of a resonance bonding length for the dangerous rock mass. When the length of the bonding section reaches the resonance bonding length, the dangerous rock mass has the largest response to the bedrock vibration. The study found that when the length of the bonding section of the dangerous rock mass is longer than the resonance bonding length, the amplitude ratio increases with the decrease of the bonding section and increases with the increase of the vibration frequency of the bedrock. When the length of the bonding section of the dangerous rock body is shorter than the resonance bonding length, the amplitude ratio decreases with the decrease of the bonding section and decreases with the increase of the vibration frequency of the bedrock. Indoor experiments were conducted by collecting the vibration time-history curves of rock blocks and stone piers and performing analysis and calculation, which proved the accuracy of the analytical results. Through the amplitude ratio of the dangerous rock mass and the bedrock, the bonding length can be calculated. This method can improve the calculation accuracy of the stability coefficient $K$ of the dangerous rock mass.

\section{Introduction}

The collapse and destruction of dangerous rock blocks on high and steep rock slopes are characterized by sudden and temporal dispersion, and they are geological disasters that are difficult to prevent from many destructive geological phenomena. The fall and collapse of dangerous rock blocks directly affect the progress of the construction project and threaten the safety of workers. Rapid evaluation of the stability of the dangerous rock mass is one of the main problems that need to be solved urgently in the current construction methods. Based on the requirements of refined management of major water conservancy projects, quickly identifying and detecting the evolving and catastrophic high-steep rock slope dangerous rock block are important. Moreover, innovating a quantitative evaluation method of stability consistent with the actual project is necessary to provide technical support for disaster prevention and treatment, reduce disaster risk, decrease disaster losses, and guarantee the construction and operation safety of slope and water conservancy projects.

In the stability evaluation of dangerous rock masses on slopes, the application of limit equilibrium method is relatively mature. Based on the failure mechanism of the slope, this method analyzes the balance between the sliding and antisliding forces of the sliding body cut by the joint surface, so that the stability of the dangerous rock mass of the slope can be assessed $[1,2]$. In addition, geometric mapping, block theory [3], numerical simulation methods [4-6], and gray system theory [7] play a role in the stability evaluation of dangerous rock masses. Regardless of the type of analytical method adopted, the analysis of the degree of bonding section between the dangerous rock block and parent rock is 
always an important step to judge the stability of the dangerous rock body.

Natural conditions such as rain, snow, earthquake, freezing, and others may cause cracking and expansion of the joint surface or softening and weakening of the bonding surface. The deterioration of the joint surface of the rock mass to a certain extent cannot provide sufficient antisliding force to maintain the stability of the rock body; thus, instability and failure occur.

To study the influence of the damage and cracking of the bonding surface on the stability of dangerous rock masses, relevant scholars started to analyze the regularity of joint failure and rock fracture mechanism from fracture mechanics and damage mechanics [8] and achieved certain results. Chen et al. $[9,10]$ determined the instability and failure mechanism of dangerous rock masses under compression-shear and tensile-shear fractures and established the calculation formula of dangerous rock stability coefficient based on fracture mechanical parameters. He et al. [11] and $\mathrm{Wu}$ et al. [12] used fracture mechanics to analyze the stress changes during the failure of tensile and shear dumping dangerous rocks and determined the influencing factors in the stability of these rocks. Appellate studies have shown that the expansion of the main joint surface of the dangerous rock mass will lead to the instability and failure of the dangerous rock mass. When the properties of the joint surface bonding material remain unchanged, the area of the bonding section will affect the stability of the dangerous rock mass. In order to judge the stability of the dangerous rock mass, it is necessary to determine the area of the bonding section of the joint surface. However, in addition to manual measurement of the dangerous rock mass, there is no effective method to measure the area of the bonding section of the dangerous rock mass.

With the continuous in-depth research on geotechnical engineering disasters, related scholars have discovered that obvious vibration signals will appear during the deformation and destruction of rock mass $[13,14]$. Yan et al. $[15,16]$ and Feng et al. [17] analyzed the ground vibration signals in the process of slope collapse and dam destruction and reconstructed the evolution process of the two disasters based on this. Kean et al. [18] and Liu et al. [19] designed a debris flow scale assessment and monitoring and early warning system based on vibration monitoring by analyzing ground vibration signals when the debris flow occurred. Manconi et al. [20] proposed a method for monitoring and positioning of collapse and landslide disasters based on vibration signal monitoring. The above studies prove the effectiveness of the research on the dynamic characteristics of rock mass, but their work mainly focuses on the analysis and processing of vibration signals. Based on this, statistical methods are used to evaluate the stability of rock mass structures, and there is a lack of quantitative analysis and evaluation of rock mass vibration processes.

As for the vibration of dangerous rock masses, relevant scholars have made good progress by establishing vibration equations of dangerous rock masses to study the influencing factors of their vibration characteristics. Ogata et al. [21] and Tanaka et al. [22] installed vibration pickup equipment on the surface of the rock mass and compared the vibration characteristics of the bedrock and the dangerous rock mass and proved that the vibration waveform of the dangerous rock mass can reflect its stability. Ma et al. [23] changed the bonding area between the concrete test block and the base and measured its natural vibration frequency, proving that the bonding area of the concrete test block will affect its natural vibration frequency. Du et al. [24] and Jia et al. [25] studied the relationship between the natural vibration frequency and bonding area of dangerous rock mass combined with the vibration equation of the dangerous rock mass and established the evaluation model of the stability of dangerous rock mass based on the natural vibration frequency; in this way, fast and accurate evaluation of the stability of dangerous rock masses can be achieved.

The stability evaluation model of dangerous rock mass $[26,27]$ based on the analysis of the vibration characteristics of dangerous rock mass is a new method of slope stability analysis and judgment in addition to the limit equilibrium method. However, the measurement of the natural vibration frequency of the rock mass depends on more precise monitoring equipment. Therefore, applying this method in engineering practice is subject to certain limitations.

In this paper, in addition to the natural vibration frequency parameters, a method is proposed for calculating the bonding length of the joint surface of the dangerous rock mass based on the amplitude ratio. By collecting the vibration time history curves of the dangerous rock mass and bedrock, the calculation of the area of the joint surface bonding zone is completed. The bonding area determines the stability of the dangerous rock mass. Therefore, the index of amplitude ratio can provide a reference for the stability evaluation of the dangerous rock mass.

\section{Joint Rock Stability and Vibration Response}

2.1. Influence of Joints on Stability of Dangerous Rock Mass. Joint fractures are common in rock bodies after experiencing geological action or man-made or environmental disturbance. On the one hand, the existence of these fractures changes the physical and mechanical properties of the rock mass; on the other hand, it is also an important factor that causes the instability and failure of the slope rock mass [28]. Figure 1 shows a common slip-type dangerous rock mass formed by a single joint plane. With the continuous penetration of the joint surface, the antisliding force provided on the dangerous rock body also continues to decline. When the antislip force is less than the sliding force of the dangerous rock body, the dangerous rock body becomes unstable and damaged, which is a commonly used method to analyze the stability of dangerous rock masses using limit equilibrium theory.

The antisliding force provided by the joint surface mainly includes the bonding and friction forces; its role should be shared by the joint section of the joint surface and 


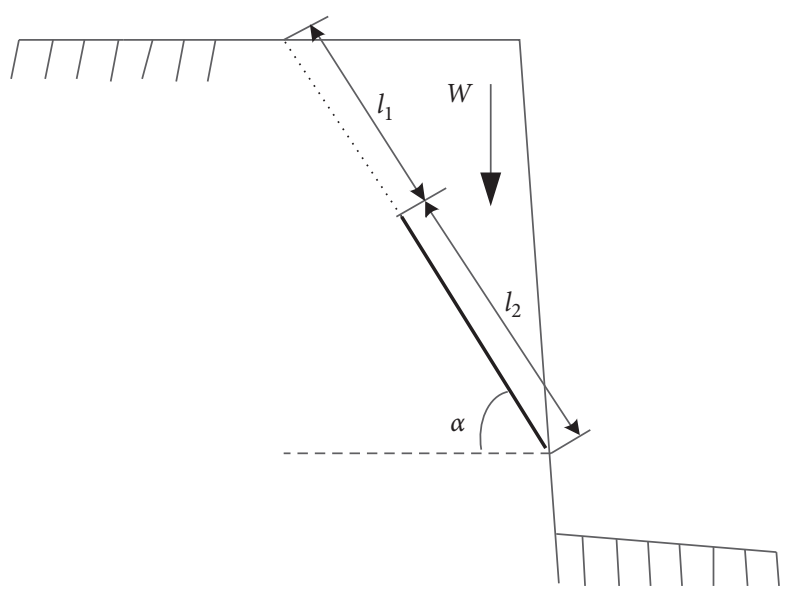

FIgURE 1: Slip-type dangerous rock mass.

bonding section of the joint surface [29]. The cohesive force $c_{1}$ of strength parameters and internal friction angle $\varphi_{1}$ of the through section of the joint surface are related to roughness and filling material, and their values can be determined or estimated by experience. Without considering the material damage, the strength parameters of the bonding section of the joint surface can be considered to be consistent with those of the rock material: $c_{2}$ and $\varphi_{2}$. Based on the assumption that the length of the continuous section of the joint plane is $l_{1}$ and the length of the unconnected section (bonding section) is $l_{2}$, the following formula for calculating the stability coefficient $K$ of a typical slippery dangerous rock mass is as follows:

$$
K=\frac{\left(\sigma \tan \varphi_{1}+c_{1}\right) l_{1}+\left(\sigma \tan \varphi_{2}+c_{2}\right) l_{2}}{W \sin \alpha} .
$$

In the formula, $W$ is the weight of the dangerous rock mass, $\alpha$ is the inclination of the joint plane, and $\sigma=W \cos \alpha /\left(l_{1}+l_{2}\right)$ represents the average normal stress on the joint surface.

In the process of rock mass from stable to unstable failure, the length of the bonding section of the joint surface continuously decreases, and the antislip force it can provide also continuously decreases. If the rock mass penetration joint surface is rough or the dip angle is small, when all of the joints are penetrated, the rock remains stable and is not damaged. However, when the rock mass penetration joint surface is smooth or the dip angle is large and the antisliding force provided by the penetration section is insufficient, the rock mass inevitably fails as the anchorage section decreases. The preceding analysis shows the influence process of the bonding section of the joint surface on the stability of dangerous rock mass. As the strength parameters $(c, \varphi)$ of the rock are much greater than those of the joint section of the joint surface, the antisliding force of the dangerous rock mass can be considered to be mainly provided by the joint section of the joint surface. Thus, the bonding length of the joint surface controls the stability of the dangerous rock mass shown in Figure 1.
If the antisliding force provided by the joint surface is not considered, the joint surface of the dangerous rock mass is regarded as the near-slip stage when it is completely penetrated. By analyzing the length of the bonding section of the dangerous rock mass, we can judge whether it reaches the near-slip state. We provide a reference for the engineering treatment of the dangerous rock mass on the slope.

2.2. Analysis of Vibration Response of Jointed Rock Mass. During the construction of the project, a certain degree of disturbance inevitably occurs in the surrounding environment. Disturbance transmitted to the dangerous rock mass of the slope causes it to produce different degrees of vibration. The vibration characteristics of the slope surface are closely related to the nature of the load and the structural characteristics of the slope. For instance, the direction and frequency of the load and the quality, size, and structural surface properties of the slope rock mass affect the vibration response of the dangerous rock mass on the slope. The appearance of the joint surface makes the slope rock mass cut, which directly changes the structural characteristics of the dangerous rock mass, so that the rock mass after the joint plane cut has a different vibration effect from the slope base rock.

To study the influence of joints on the vibration response of dangerous rock masses, we can assume that the dangerous rock mass formed by the joint plane is a rigid body of mass $M$, and the anchorage section's constraint on the dangerous rock mass is composed of spring $K$ and damper $C$ [30]. As a result, the rock mass after cutting the joint surface is simplified into a mass-spring-damped vibration system. If only one rock mass after cutting a single joint surface is considered, then this system is a single-degree-of-freedom vibration system. As a result, the rock mass cut by the joint surface is simplified into a mass-spring-damped vibration system. If only single joint surface cutting is considered, then this system is a single-degree-of-freedom vibration system. As shown in Figure 2, the existence of the joint surface cuts the slope into bedrock $M_{1}$ and dangerous rock mass $M_{2}$. 


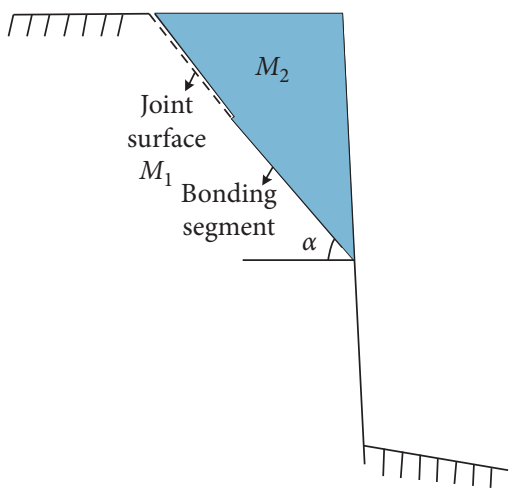

(a)

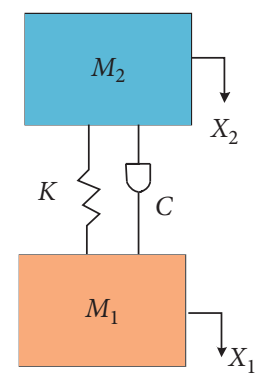

(b)

FIgURe 2: Vibration model of jointed rock mass.

Combined with the preceding analysis, a slope vibration model is established, as shown in Figure 2(b).

When the bedrock $M_{1}$ is excited by the external environment and generates vibration, the vibration energy is transmitted to the rock and soil body. The dangerous rock mass $M_{2}$ receives vibration energy through the bonding section of the joint surface, which in turn generates vibration. If only the vibration in the direction of the vertical joint plane is considered, when the bedrock $M_{1}$ vibrates at $x_{1}=a \cdot e^{i w t}$, the vibration of the dangerous rock mass $M_{2}$ is expressed as follows:

$$
m_{2} \ddot{x}_{2}+c \dot{x}_{2}+k x_{2}=k x_{1}+c \dot{x}_{1}
$$

where $x_{1}$ is the displacement of bedrock $M_{1}, x_{2}$ is the displacement of dangerous rock mass $M_{2}, k$ is the stiffness of the bonding section, and $c$ is the damping of the bonding section.

The amplitude $b$ of $M_{2}$ can be obtained by solving formula (2) through the following equation:

$$
b=a \sqrt{\frac{1+(2 \xi \lambda)^{2}}{\left(1-\lambda^{2}\right)^{2}+(2 \xi \lambda)^{2}}}
$$

The physical quantities included in the formula are

$M_{2}$ natural vibration frequency: $f_{2}=\sqrt{k / m_{2}}$

Relative vibration frequency: $\lambda=w / f_{2}$

Damping ratio: $\xi=c / 2 \sqrt{\mathrm{km}_{2}}$

It can be seen from equations (2) and (3) that the bonding section will affect the stiffness and damping of the dangerous rock mass when it vibrates, causing the dangerous rock mass and the parent rock to produce different amplitudes. Formula (1) has shown that the length of the bonding section determines the stability of the slip-type dangerous rock mass. Therefore, we can determine the stability of the dangerous rock mass by analyzing the ratio of the amplitude of the dangerous rock mass to the bedrock.

\section{Relationship between Amplitude Ratio and Bonding Length}

3.1. Relationship between Amplitude Ratio and Stiffness of Joint Surface. When the vibration is transmitted from the bedrock to the dangerous rock mass, the dangerous rock mass reaches its maximum reaction in a short time. In this process, the damping in the anchor segment does not absorb a larger amount of energy from the entire vibration system. Therefore, during the analysis, the damping can be ignored, and the vibration of the dangerous rock mass can be simplified as undamped forced vibration.

At this point, the amplitude ratio of the dangerous rock $M_{2}$ and the bedrock $M_{1}$ can be written as follows:

$$
R=\frac{b}{a}=\left|\frac{1}{\lambda^{2}-1}\right|=\left|\frac{1}{w^{2} / f_{2}^{2}-1}\right|=\left|\frac{1}{w^{2} m_{2} / k-1}\right| .
$$

Based on equation (4), the relationship curve between the joint surface stiffness and the rock mass amplitude ratio can be obtained. As shown in Figure 3, the horizontal axis represents the stiffness of the joint surface, and the vertical axis represents the amplitude ratio of the dangerous rock mass.

The figure shows that, with the increase of the stiffness of the anchorage section, the amplitude ratio of the dangerous rock and bedrock increases first and then decreases, and the extreme value is obtained when $k=w^{2} m_{2}$. The dangerous rock mass has a resonance effect at the extreme point $w=f_{2}$, that is, when the vibration frequency of the dangerous rock mass is equal to the vibration frequency of the bedrock. 


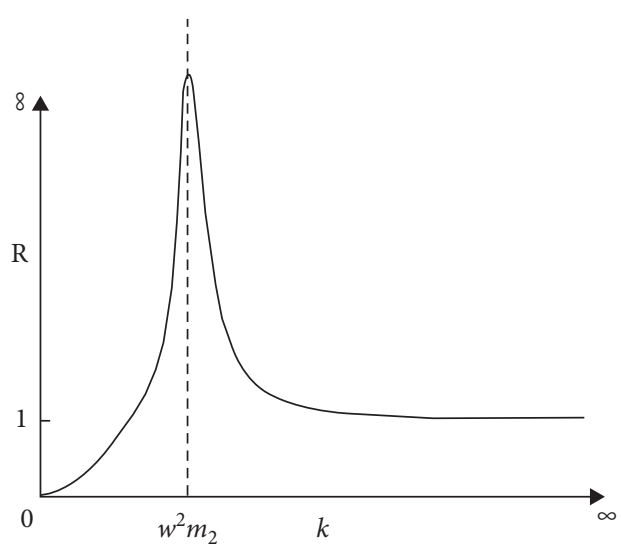

Figure 3: Relationship between stiffness and amplitude ratio of bonding section of dangerous rock mass.

For dangerous rock masses, when the joint surface is completely penetrated and no bonding section exists, the dangerous rock mass is completely separated from the bedrock. At this time, the rigidity of the joint surface is close to 0 , and the vibration of the bedrock cannot be transmitted to the dangerous rock mass. Time amplitude ratio $R=0$. When no obvious penetrating area exists on the joint surface, the dangerous rock mass and bedrock constitute a whole, and the joint surface has the highest rigidity. At this time, the vibration response of the two is the same, and the amplitude ratio is $R=1$.

\subsection{Relationship between Stiffness of Joint Surface and Length} of Bonding Section. Figure 3 has initially shown the relationship between the stiffness of the joint surface and the amplitude ratio, and the length of the bonding section of the joint surface is closely related to the stability of the dangerous rock mass. If the relationship between the length of the bonding section and the stiffness of the joint surface can be determined, the bonding length of the joint surface can be determined from the amplitude ratio of the dangerous rock mass to the bedrock, and the stability of the dangerous rock mass can be judged.

The stiffness $k$ is a physical quantity that characterizes the elastic deformation ability of the material when it is subjected to external forces and can be regarded as the force required when the material generates unit displacement [29]. As the stress of the joint surface is mainly borne by its bonding section, its stiffness can be calculated by the parameters of the bonding section as follows:

$$
k=\frac{E S}{D},
$$

where $E$ is the elastic modulus of the rock mass, $S$ is the area of the bonding section, and $D$ is the thickness of the bonding section.

Without considering the damage of the rock material, we can regard the elastic modulus of the bonding section as the elastic modulus of the rock. At the same time, we can assume that the thickness of the joint surface is basically unchanged during the dangerous process when the rock changes from stable to unstable, and its stiffness is mainly affected by the joint surface area $S$. The area of the bonding zone is the product of the length and width of the bonding surface: $S=b^{*} l$. When analyzing dangerous rock masses per unit thickness, the length $l_{2}$ of the bonding section can be used to replace the bonding area $S$; then the amplitude ratio formula can be rewritten as

$$
R=\frac{b}{a}=\left|\frac{1}{\lambda^{2}-1}\right|=\left|\frac{1}{w^{2} m_{2}(D / E l)-1}\right|=\left|\frac{1}{u\left(w^{2} / l\right)-1}\right|,
$$

where $u=m_{2} D / E$. The above formula expresses the relationship between the amplitude ratio of dangerous rock mass to bedrock and the length of the bonding section of dangerous rock mass without considering the damping effect. Combining with the location of the resonance peak in Figure 3, we can determine the relationship between the amplitude ratio of the dangerous rock mass and the bonding section of the joint surface. With the penetration of the joint surface of the dangerous rock mass, the vibration amplitude of the dangerous rock mass affected by the bedrock gradually increases first. When the length of the bonding section weakens to $u w^{2}$, it reaches its maximum amplitude. Thereafter, when the crack continues to expand and the length of the bonding section decreases, the amplitude of the dangerous rock mass also continues to decrease. If the length of the bonding section remains unchanged, when $l_{2}>u w^{2}$, the amplitude ratio increases with the increase of bedrock vibration frequency $w$; and when $l_{2}<u w^{2}$, the amplitude ratio increases as the bedrock vibration frequency $w$ decreases.

The preceding analysis shows that the relative size of the bonding length $l_{2}$ and $u w^{2}$ is an important reflection of the vibration characteristics of the dangerous rock mass. When the length of the bonding section is equal to $u w^{2}$, the vibration frequency of the dangerous rock mass is equal to the vibration frequency of the bedrock, and the two generate resonance. Therefore, the length of the bonding section at $l_{0}=u w^{2}$ is referred to as the resonant bonding length of the dangerous rock mass. 
3.3. Measuring Method of Bonding Length Based on Amplitude Ratio. Based on equation (6), the calculation formula of the bonding length of the joint surface can be obtained as follows:

$$
l_{2}= \begin{cases}\frac{w^{2} u R}{(R+1)}, & l_{2}<l_{0}, \\ \frac{w^{2} u R}{(R-1)}, & l_{2}>l_{0} .\end{cases}
$$

The preceding equation shows that if the parameter $u$ of the joint surface is known, the vibration frequency $w$, vibration amplitude $a$ of the bedrock, and vibration amplitude $b$ of the dangerous rock mass can be obtained by measurement. The calculated amplitude ratio $R$ and the measured $w$ are brought into equation (7) to obtain the bonding length $l_{2}$ of the joint surface. When $l_{2}$ is known, the stability coefficient of the slip-type dangerous rock mass can be calculated according to the relevant parameter values through equation (1).

Equation (7) needs to judge the relationship between the actual length of the bonding section of the joint surface and the resonance bonding length in advance. The preceding analysis shows that the relationship between the amplitude ratio $R$ and the bedrock vibration frequency $w$ will change with the length of the bonding section. If we perform multiple measurements of the vibration of the bedrock and dangerous rock mass, we can obtain the bedrock vibration frequencies $w_{1}$ and $w_{2}$ and the corresponding amplitude ratios $R_{1}$ and $R_{2}$. The relative size relationship between the bonding length and resonant bonding length of the joint surface can be judged by the change trend of the amplitude ratio with the vibration frequency of the bedrock. Then, the calculation formula of the bonding length of the joint surface is determined as follows:

$$
\begin{cases}l_{2}>l_{0}, & w_{1}>w_{2}, R_{1}>R_{2}, \\ l_{2}<l_{0}, & w_{1}<w_{2}, R_{1}>R_{2} .\end{cases}
$$

\section{Verification Test}

4.1. Brief Description of Experimental Process. The relationship between the amplitude ratio of the dangerous rock mass and the strength of the joint surface is analyzed. We prove through theoretical derivation that, by measuring the vibration frequency of the bedrock and the amplitude ratio between the dangerous rock body and bedrock, the bonding length of the joint surface of the dangerous rock body can be determined. A verification test was designed to validate the accuracy of the preceding theory. By changing the vibration frequency of the bedrock and measuring the amplitude ratio of the dangerous rock mass to the bedrock at different vibration frequencies, we calculated the length of the bonding section of the joint surface and compared it with the actual value.

In the experiment, the replacement of the bedrock is a stone pier, and the replacement of the dangerous rock mass is a stone with a size of $15 \times 15 \times 15 \mathrm{~cm}$. The stone and pier are bonded with plastic plates to simulate the joint surface. The mass of the stone is $2.35 \mathrm{~kg}$, the thickness of the plastic plate is $3 \mathrm{~cm}$, and the elastic modulus is $172 \mathrm{kPa}$. The small exciter with adjustable frequency is used to excite the stone pier. The schematic of the experiment is shown in Figure 4.

During the experiment, the area of the plastic plate is gradually adjusted to $5 \times 15 \mathrm{~cm}$ and $10 \times 15 \mathrm{~cm}$, and the frequency of the exciter is adjusted to $10 \mathrm{~Hz}$ and $20 \mathrm{~Hz}$, respectively. Doppler laser vibrometer was used to measure the vibration of the stone pier and rock block in the direction of the vertical joint plane. A total of 4 sets of data were measured in the experiment. Figure 5 shows the vibration curves of the bedrock and block when the vibration frequency of the stone pier is $20 \mathrm{~Hz}$ and the area of the plastic plate is $10 \times 15 \mathrm{~cm}$.

4.2. Analysis of Experimental Results. Figure 5 shows that whether a stone pier or a block is bonded to the surface, the acceleration time-history curve is not a simple periodic motion; thus, the amplitude cannot be directly extracted for comparison. To solve this problem, when calculating the amplitude ratio, we select the acceleration time-history curve of the stone pier and the rock block and use the ratio of the root mean square (RMS) amplitude of the two as the parameter to evaluate the vibration characteristics of the block. The formula for calculating the RMS amplitude is as follows [29]:

$$
\bar{a}=\sqrt{\frac{\sum_{i=1}^{n} a_{i}^{2}}{n}},
$$

where $a_{i}$ is the acceleration in the measured time-history curve and the amplitude ratio of the rock block to the stone pier is calculated according to the preceding formula. The obtained rock-block vibration test results are shown in Table 1.

The table shows that before and after the foam board is cut, increasing the excitation frequency of the exciter increases the amplitude ratio of the dangerous rock body, which indicates that the bonding length of the foam board before and after cutting is greater than its resonance bonding length. From this condition, we can determine the calculation formula of the bonding section of the joint surface given in (7). With the parameters of plastic plates and rocks brought into formula (7), the calculated length of the bonding section of the rock block can be obtained as shown in Table 2.

The results show that the calculated bonding length of the rock block is relatively close to its actual length. This condition indicates that one can quickly calculate the bonding section of the rock joint surface and provide a reference for the stability evaluation of the dangerous rock mass by collecting the vibration curve of the rock block and stone pier and calculating the amplitude ratio [31]. 


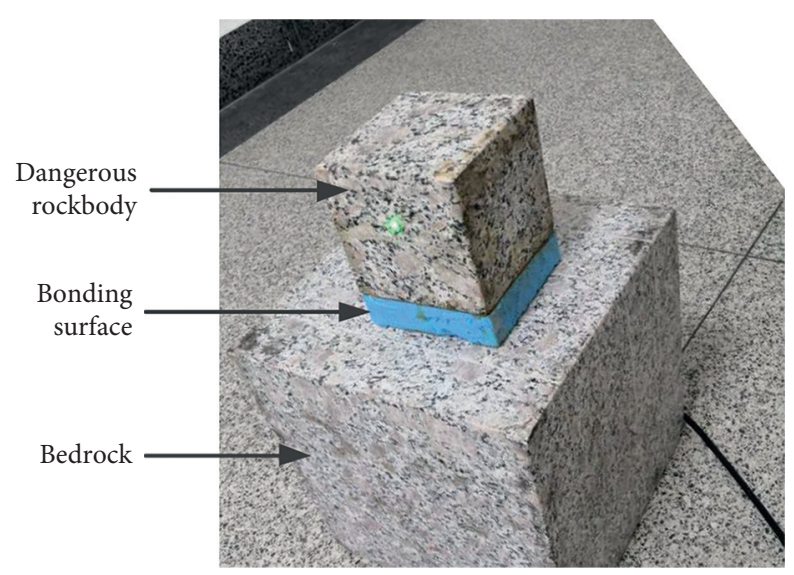

FIgURE 4: Schematic of indoor test process.

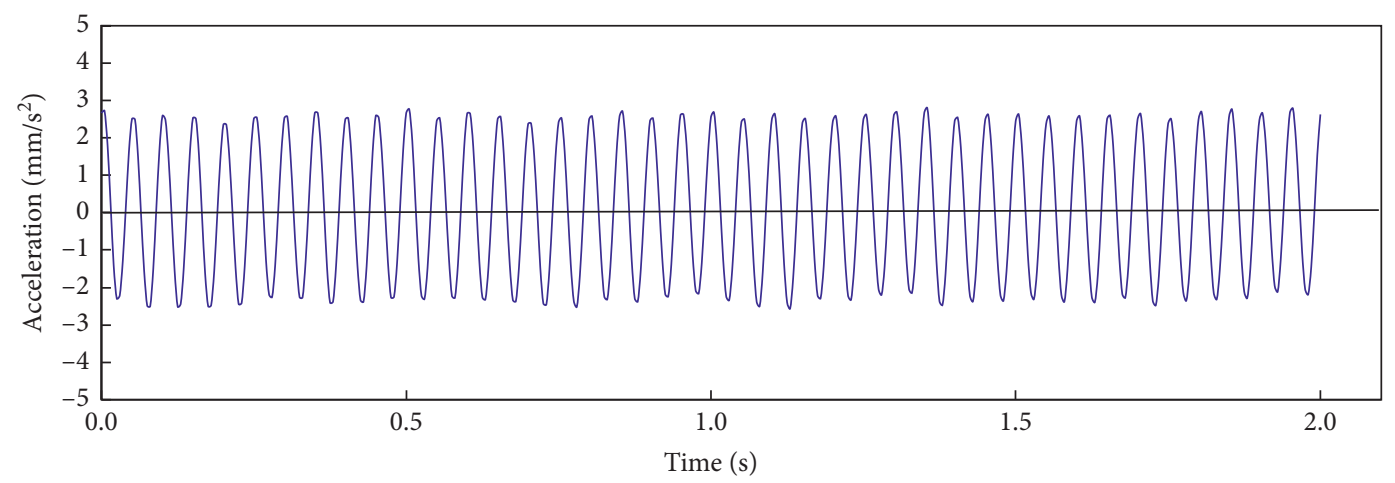

(a)

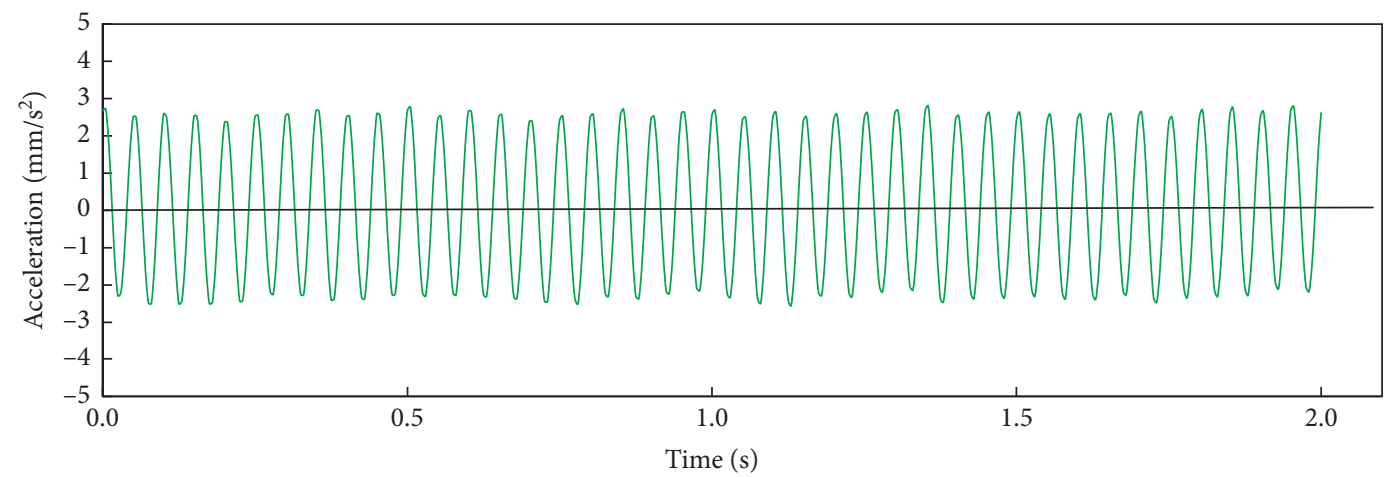

(b)

FIgURE 5: Vibration curves of stone piers and stones. (a) Stone pier vibration curve. (b) Block vibration curve.

TABle 1: Rock-block vibration test results.

\begin{tabular}{lcc}
\hline Excitation frequency & Plastic board area & Amplitude ratio \\
\hline 10 & $5 \times 15 \mathrm{~cm}$ & 1.0202 \\
20 & $5 \times 15 \mathrm{~cm}$ & 1.0797 \\
10 & $10 \times 15 \mathrm{~cm}$ & 1.0101 \\
20 & $10 \times 15 \mathrm{~cm}$ & 1.0364 \\
\hline
\end{tabular}

TABLE 2: Calculation result of length of rock block.

\begin{tabular}{lcc}
\hline $\begin{array}{l}\text { Excitation } \\
\text { frequency }(\mathrm{Hz})\end{array}$ & $\begin{array}{c}\text { Actual bonding } \\
\text { length }(\mathrm{cm})\end{array}$ & $\begin{array}{c}\text { Calculated bonding } \\
\text { length }(\mathrm{cm})\end{array}$ \\
\hline 10 & 5 & 4.66 \\
20 & 5 & 5.25 \\
10 & 10 & 9.23 \\
20 & 10 & 10.51 \\
\hline
\end{tabular}




\section{Conclusion}

(1) The characteristics of the bonding section play a vital role in the stability of the dangerous rock mass. This paper analyzes the influence of the bonding section on the vibration response of the dangerous rock mass through the vibration equation of the slipping dangerous rock mass formed by the cutting of a single joint plane. The result proves that the stability of the slip-type dangerous rock mass is judged by measuring the vibration response of the dangerous rock mass and the bedrock.

(2) Through the analysis of the relationship between the length of the bonding section and the amplitude ratio of the dangerous rock mass, the concept of resonance bonding length was proposed. The bonding section on both sides of the resonance bonding length has opposite effect on the amplitude ratio of the dangerous rock mass.

(3) It was proved that the length of the bonding section could be calculated reliably by the amplitude ratio. The theoretical analysis results were verified through experiments. This method provides a new reference for evaluating the stability of dangerous rock masses.

(4) The bonding area between the dangerous rock mass and the bedrock determines the stability of the dangerous rock mass. As the bonding area decreases, the amplitude ratio between the dangerous rock mass and the bedrock will also change. The amplitude ratio reflects the stability of the dangerous rock mass. If we can measure the amplitude ratio of the dangerous rock mass to the bedrock through the monitoring equipment, we can monitor the change trend of the stability of the dangerous rock mass, which is of great significance for early warning of instability and failure of rock slopes.

\section{Discussion}

(1) In this paper, when analyzing the vibration equation of the slip-type dangerous rock mass, the rock mass was simplified to a single-degree-of-freedom rigid body, which would cause the difference between the calculation result of the bonding length based on the amplitude ratio and the actual value. It is necessary to continue to study this issue in depth.

(2) The main research in this paper is the slip-type dangerous rock mass formed by the cutting of a single joint plane. The boundary conditions of this kind of dangerous rock mass are relatively clear and the stress characteristics are simple. However, there are a large number of dangerous rock masses with unclear boundary conditions and complex stress characteristics in actual engineering. For this kind of dangerous rock mass controlled by multiple structural planes, the calculation formula proposed in this article will no longer be applicable.
(3) With the rapid development of vibration monitoring technology and continuous breakthroughs in theoretical research, we believe that the stability evaluation method of dangerous rock mass based on the amplitude ratio of the dangerous rock mass and the bedrock proposed in this paper will have good application value.

\section{Data Availability}

The data used to support the findings of this study are included within the supplementary information file.

\section{Conflicts of Interest}

The authors declare that they have no conflicts of interest.

\section{Acknowledgments}

This project was financially supported by the National Key R\&D Plan (Grant no. 2019YFC1509600) and the National Natural Science Foundation (Grant no. 41572274). Special gratitude is also extended to the participants who have contributed to this work.

\section{References}

[1] H. Kumsar, O. Aydan, and R. Ulusay, "Dynamic and static stability assessment of rock slopes against wedge failures," Rock Mechanics and Rock Engineering, vol. 33, no. 1, pp. 31-51, 2000.

[2] W. Liu and R. Huang, "Study on quantitative evaluation of perilous rock stability," Subgrade Engineering, vol. 6, pp. 5157, 2014.

[3] Y. Xiao, Q. Xu, C. Liu et al., "Review on the research of block stability," Yangtze River, vol. 48, no. 1, pp. 130-133, 2017.

[4] G. H. Shi, "Discontinuous deformation analysis: a new numerical model for the statics and dynamics of deformable block structures," Engineering Computations, vol. 9, no. 2, pp. 157-168, 1992.

[5] N. Li, S. Guo, and X. Yao, "Further study of stability analysis methods of high rock slopes," Rock and Soil Mechanics, vol. 39, no. 2, pp. 397-406, 2018.

[6] Y. Chen, J. Xu, X. Huo, and J. Wang, "Numerical simulation of dynamic damage and stability of a bedding rock slope under blasting load," Shock and Vibration, vol. 2019, Article ID 9616859, 13 pages, 2019.

[7] Q. Xie and Y. Xia, "Comprehensive assessment method of stability of critical rock-block mass and its application," Rock and Soil Mechanics, vol. 23, no. 6, pp. 775-777, 2002.

[8] H. Xie and F. Gao, "The mechanics of cracks and a statistical strength theory for rocks," International Journal of Rock Mechanics \& Mining Ences, vol. 37, no. 3, pp. 477-488, 2000.

[9] S. Chen, H. Chen, M. Yang, T. Chen, and K. Guo, "Analysis on fracture mechanics of unstable rock," World Journal of Engineering and Technology, vol. 4, no. 3, pp. 69-75, 2016.

[10] H. Chen, X. Xian, and H. Tang, "Stability analysis method for perilous rock by fracture mechanics," Journal of Chongqing University (Natural Science Edition), vol. 32, no. 4, pp. 434437, 2009.

[11] Q. He, L. Wu, B. Li, and H. Wu, "Factors of instability of toppling unstable rocks subjected to tensile and shear 
stresses," Journal of Hohai University (Natural Sciences), vol. 45, no. 3, pp. 235-242, 2017.

[12] L. Z. Wu, B. Li, R. Q. Huang, and Q. Z. Wang, "Study on mode I-II hybrid fracture criteria for the stability analysis of sliding overhanging rock," Engineering Geology, vol. 209, pp. 187195, 2016.

[13] D. Li, X. Liu, X. Li, and Y. Liu, "The impact of microearthquakes induced by reservoir water level rise on stability of rock slope," Shock and Vibration, vol. 2016, Article ID 7583108, 13 pages, 2016.

[14] K. Zhang, S. Ji, Y. Zhang, J. Zhang, and R. Pan, "MEMS inertial sensor for strata stability monitoring in underground mining: an experimental study," Shock and Vibration, vol. 2018, Article ID 4895862, 8 pages, 2018.

[15] Y. Yan, Y. Cui, J. Guo, S. Hu, Z. Wang, and S. Yin, "Landslide reconstruction using seismic signal characteristics and numerical simulations: case study of the 2017 " 6.24 " Xinmo landslide,” Engineering Geology, vol. 270, Article ID 105582, 2020.

[16] Y. Yan, Y. Cui, S. Hu et al., "Seismic signal recognition and interpretation of the 2019 " 7.23 " Shuicheng landslide by seismogram stations," Landslides, vol. 17, pp. 1191-1206, 2020.

[17] Z.-Y. Feng, H.-Y. Huang, and S.-C. Chen, "Analysis of the characteristics of seismic and acoustic signals produced by a dam failure and slope erosion test," Landslides, vol. 17, no. 7, pp. 1605-1618, 2020.

[18] J. W. Kean, J. A. Coe, V. Coviello, J. B. Smith, S. W. McCoy, and M. Arattano, "Estimating rates of debris flow entrainment from ground vibrations," Geophysical Research Letters, vol. 42, no. 15, pp. 6365-6372, 2015.

[19] D. Liu, X. Leng, F. Wei, S. Zhang, and Y. Hong, "Visualized localization and tracking of debris flow movement based on infrasound monitoring," Landslides, vol. 15, no. 5, pp. 879-893, 2018.

[20] A. Manconi, M. Picozzi, V. Coviello, F. De Santis, and L. Elia, "Real-time detection, location, and characterization of rockslides using broadband regional seismic networks," Geophysical Research Letters, vol. 43, no. 13, pp. 6960-6967, 2016.

[21] K. Ogata, H. Matsuyama, and K. Amano, "Evaluation of the rockfall potential utilizing the characteristics of vibration," Doboku Gakkai Ronbunshu, vol. 2003, no. 749, pp. 123-135, 2003.

[22] H. Tanaka, K. Fujisawa, and K. Asai, "Identifying unstable rock blocks by measuring micro-tremors and vibration on cliffs," Advances in Geosciences, vol. 14, no. 14, pp. 165-171, 2008.

[23] G. Ma, K. Sawada, and H. Saitoh, "Study on evaluating rock block stability by using a remotely positioned laser Doppler vibrometer," International Journal of Geomate, vol. 2, no. 2, pp. 247-252, 2012.

[24] Y. Du, M. Xie, F. Lv et al., "New method for dynamic analysis of rock slope stability based on modal parameters," Chinese Journal of Geotechnical Engineering, vol. 37, no. 7, pp. 1334-1339, 2015.

[25] X. Yang, S. Shu, and F. Wu, "Simple geology-geometry analytical procedure on stability of tunnel critical rock-block mass," Rock and Soil Mechanics, vol. 27, no. 6, pp. 890-894, 2006.

[26] D. M. Siringoringo and Y. Fujino, "Experimental study of laser Doppler vibrometer and ambient vibration for vibrationbased damage detection," Engineering Structures, vol. 28, no. 13, pp. 1803-1815, 2006.
[27] A. B. Stanbridge, M. Martarelli, and D. J. Ewins, "Measuring area vibration mode shapes with a continuous-scan LDV," Measurement, vol. 35, no. 2, pp. 181-189, 2000.

[28] X. Li, R. Zhu, and W. Zhu, "Macro-damage mechanics of jointed rock mass," in Proceedings of the International Symposium on Assessment and Prevention of Failure Phenomena in Rock Engineering, pp. 79-85, Rotterdam, Netherlands, April 1993.

[29] Y. Du, E. Yan, J. Cai et al., "Reliability analysis method on unstable rock mass controlled by discontinuous structure," Journal of Harbin Institute of Technology, vol. 51, no. 8, pp. 120-127, 2019.

[30] L. Zheng, "Specific vibration property and mechanism of rockmass in railway slopes," Chinese Journal of Rock Mechanics and Engineering, vol. 13, no. 1, pp. 69-78, 1994.

[31] X. Liu, "Experimental study on stiffness characteristics of rockmass structural face in TGP," Journal of Yangtze Riverentific Research Institute, vol. 15, no. 2, pp. 26-28, 1998. 